\title{
Regulation of the Metabolism of Some Alkylated Amines in the Yeasts Candida utilis and Hansenula polymorpha
}

\author{
By K. B. ZWART AND W. HARDER* \\ Department of Microbiology, University of Groningen, Kerklaan 30, 9751 NN Haren, \\ The Netherlands
}

(Received 27 April 1983)

\begin{abstract}
The initial metabolism of some methylated and ethylated amines, which were used as a nitrogen source but not as the sole carbon source by the yeasts Candida utilis and Hansenula polymorpha, involved a peroxisomal amine oxidase which produced ammonium ions, hydrogen peroxide, and formaldehyde or acetaldehyde. The aldehydes so formed were either oxidized via their corresponding carboxylic acids or, depending on the organism and the aldehyde, also partly assimilated into cell material. The synthesis of amine oxidase, which was paralleled by the development of peroxisomes in the cells, was repressed in the presence of ammonium ions and derepressed under nitrogen limitation. Amines were not required as inducers of enzyme synthesis. Utilization of ethylated amines, but not of methylated amines, as a nitrogen source resulted in a significant increase in cell yield.

In both yeasts ammonium ions were assimilated mainly by way of NADPH-dependent glutamate dehydrogenase. The activity of this enzyme increased drastically in cells grown under ammonium or amine limitation or, under carbon limitation, in the presence of amines as the sole source of nitrogen. Under the latter conditions free ammonium was not detectable in the culture supernatant, while the amount of amines utilized was just sufficient to account for the amount of cell material produced. This indicated that during growth with amines as the nitrogen source the physiological condition that the cells experience is in fact one of ammonium limitation. Our results suggested that the rate of amine oxidation was determined by the intracellular concentration of ammonium and determined via repression of amine oxidase synthesis. Due to this control and the high nitrogen to carbon ratio of amines, sustained growth of the methylotrophic yeast $H$. polymorpha on methylamine and of both species on ethylamine as a carbon source is not possible, even though these organisms are able to grow on the related compounds methanol and ethanol.
\end{abstract}

\section{INTRODUCTION}

Many yeasts are able to utilize various alkylated amines as the sole nitrogen source, but not as their sole source of carbon for growth (van Dijken \& Bos, 1981). In the yeasts Candida utilis and Hansenula polymorpha, the key enzyme in the metabolism of methylamine is amine oxidase (Zwart et al., 1980). This peroxisomal enzyme catalyses the following reaction.

$$
\mathrm{RCH}_{2} \mathrm{NH}_{2}+\mathrm{O}_{2}+\mathrm{H}_{2} \mathrm{O} \longrightarrow \mathrm{RCHO}+\mathrm{H}_{2} \mathrm{O}_{2}+\mathrm{NH}_{3}
$$

In the filamentous fungus Aspergillus niger (van Dijken \& Veenhuis, 1980) and the yeast Candida boidinii (Haywood \& Large, 1981) this enzyme is also involved in growth with methylamine as the sole nitrogen source. Amine oxidase from $C$. boidinii has been purified to near homogeneity. This enzyme has a broad substrate specificity for primary alkylated amines, but does not react with secondary and tertiary amines (Haywood \& Large, 1981).

Little is known about the physiology of primary amine utilization in yeasts. It is evident (equation 1) that their oxidation results in the formation of an aldehyde. In view of this, the observation that these amines cannot support growth as the sole carbon source (van Dijken \& Bos, 1981) is rather puzzling (see Fig. 1). In the case of methylamine utilization formaldehyde is 


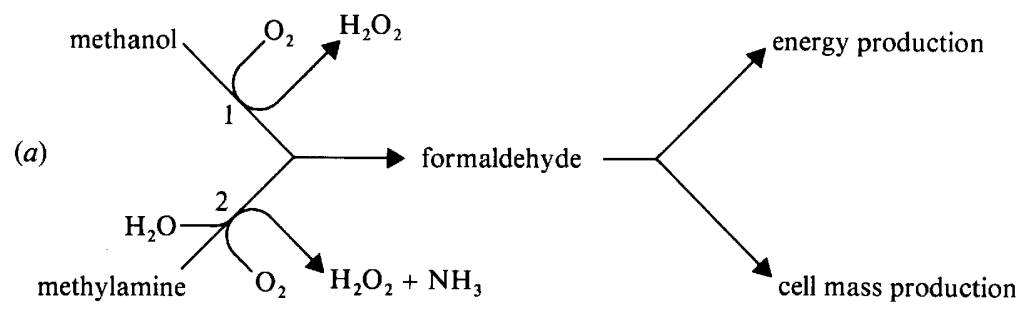

(b)

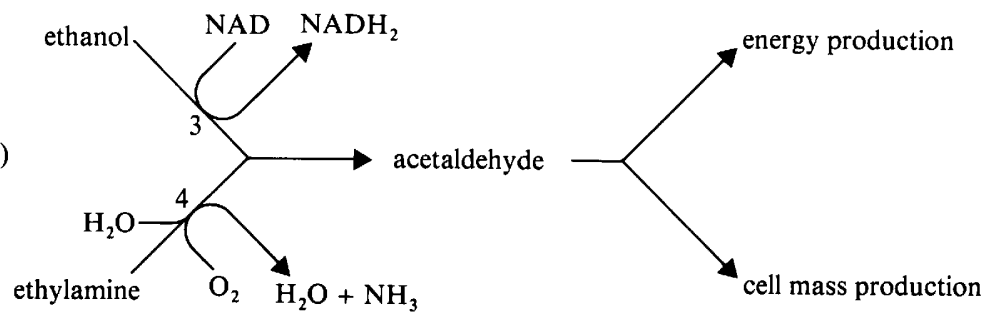

Fig. 1. Formaldehyde and acetaldehyde as common intermediates of methanol and methylamine metabolism $(a, H$. polymorpha) and ethanol and ethylamine metabolism $(b, H$. polymorpha and $C$. utilis) (1, alcohol oxidase; 2, amine oxidase; 3, alcohol dehydrogenase).

produced which, in the methylotrophic yeast $H$. polymorpha, can be either further oxidized via formate to $\mathrm{CO}_{2}$ by NAD-dependent formaldehyde and formate dehydrogenases (Zwart et al., 1980 ) or assimilated into cell material via the xylulose monophosphate pathway (van Dijken et $a l ., 1978$ ). In the non-methylotrophic yeast $C$. utilis, assimilation of formaldehyde is not possible, but this compound can be oxidized to $\mathrm{CO}_{2}$ by NAD-dependent formaldehyde and formate dehydrogenases. In this yeast formaldehyde metabolism can therefore only yield metabolic energy. During ethylamine utilization, the first product in both yeasts is acetaldehyde. This compound is also produced in cells which utilize ethanol as a source of carbon. In these cells acetaldehyde, after conversion to acetyl-CoA, can be used both for energy generation and for carbon assimilation. Growth of the yeasts used in the present study is also possible in media with methanol (H.polymorpha; Veenhuis et al., 1981) or ethanol (both species) as a carbon source and methylamine or ethylamine as the nitrogen source. Because utilization of ammonium sulphate as a nitrogen source does not result in the formation of reduced nicotinamide nucleotides, at least a difference in cell yield between cells grown in the presence of ammonium sulphate and those grown with alkylated amines as the nitrogen source must be expected.

We have investigated the metabolism of several amines as the sole nitrogen source for growth and their effect on cell yield in $H$. polymorpha and $C$. utilis. In addition we have studied possible effects of ammonium ions on the activity and synthesis of amine oxidase in the latter organism. The results presented in this paper show that the high nitrogen to carbon ratio of amines is an important factor in determining their metabolic fate. Through control mechanisms which carefully adjust the rate of ammonia production to the requirement of the cells, the rate of amine utilization is limited. It is thought that these mechanisms also effectively prevent the utilization of amines as a sole carbon source for growth.

\section{METHODS}

Organisms and cultivation. Candida utilis NCYC 321 and Hansenula polymorpha de Morais et Maya CBS 4732 were grown in chemostat cultures at $30^{\circ} \mathrm{C}$ and $37^{\circ} \mathrm{C}$ respectively, in the mineral medium of van Dijken et al. (1976), at a controlled dissolved oxygen concentration of $50 \%$ air saturation. Ammonium sulphate, methylamine, dimethylamine, trimethylamine, ethylamine or diethylamine at various initial concentrations were used as the nitrogen source. Cultures of $C$. utilis cells were supplied with various concentrations of glucose, ethanol or glycerol, and cultures of $H$. polymorpha cells with glucose $\left(2 \cdot 5 \mathrm{~g}^{-1}\right)$ as a carbon source. 
Determination of the concentration of nitrogen and carbon sources. Ammonium sulphate was determined enzymically with glutamate dehydrogenase (Boehringer, Mannheim, F.R.G.). Methylamine, dimethylamine, trimethylamine, ethylamine and ethanol were determined by gas chromatography according to the method of Meiberg \& Harder (1979). Glucose was determined enzymically with the glucose oxidase-peroxidase system (Boehringer).

Determination of formaldehyde, formate, acetaldehyde and acetate. Formaldehyde was determined by the method of Nash (1953), formate according to Lang \& Lang (1972), acetaldehyde as its phenylhydrazone at $305 \mathrm{~nm}$ and acetate by gas chromatography using the method of Laanbroek et al. (1977).

Determination of organic carbon. Organic carbon was measured using a Beckman total carbon analyser model 915A, connected to an infra-red analyser (Beckman, model 865), with sodium phthalate as a standard. Inorganic carbon concentrations in the samples were negligible.

Enzyme assays. The preparation of cell-free extracts and the estimation of amine oxidase activity was as described previously (Zwart et al., 1980). Alcohol oxidase (EC 1.1.3.13), formaldehyde dehydrogenase (EC 1.2.1.1) and formate dehydrogenase (EC 1.2.1.2) were measured following the procedure of van Dijken et al. (1976). Catalase (EC 1.11.1.6) was measured according to Lück (1963), and NAD- and NADP-dependent glutamate dehydrogenase (EC 1.4.1.2 and 1.4.1.4) as described for the commercial enzyme (Boehringer). Glutamine synthetase (EC 6.3.1.2) was estimated according to Mecke (1974) and glutamate synthase (EC 1.4.1.14) according to Roon et al. (1973). Isocitrate lyase (EC 4.1.3.1) was measured according to Dixon \& Kornberg (1959), and triokinase (EC 2.7.1.28) according to the method of van Dijken et al. (1978). Enzyme activities were determined at $37^{\circ} \mathrm{C}$ for $H$. polymorpha and at $30^{\circ} \mathrm{C}$ for $\mathrm{C}$. utilis and expressed as follows: amine oxidase and alcohol oxidase as $\mathrm{nmol}$ oxygen consumed $\mathrm{min}^{-1}$ (mg protein) ${ }^{-1}$, catalase as $\Delta A_{240} \mathrm{~min}^{-1}\left(\mathrm{mg}^{2}\right.$ protein) $)^{-1}$, and all other activities as nmol substrate consumed or product formed $\min ^{-1}$ (mg protein) ${ }^{-1}$.

Protein determination. Protein was determined by the Lowry method using bovine serum albumin as the standard.

Electron microscopy. Whole cells were fixed in $1.5 \%(\mathrm{w} / \mathrm{v}) \mathrm{KMnO}_{4}$ for $20 \mathrm{~min}$ at room temperature, dehydrated in a graded alcohol series and embedded in Epon 812. Thin sections were cut with a diamond knife and examined in a Philips EM300.

\section{RESULTS}

\section{Metabolism of alkylated amines in C. utilis and $H$. polymorpha}

Previously (Zwart et al., 1980) we have shown that in the yeasts C. utilis and H.polymorpha the complete oxidation of methylamine to carbon dioxide and ammonia is mediated by amine oxidase and formaldehyde and formate dehydrogenases. Of these enzymes amine oxidase is peroxisomal. Van Dijken \& Bos (1981) reported that many yeasts have the capacity to utilize a broad range of alkylated amines as the sole nitrogen source. Since little is known about the metabolism of amines in yeasts, we have studied the effect of the utilization of a number of these compounds on the activity of enzymes possibly involved in their metabolism. For that purpose $C$. utilis and $H$. polymorpha were grown in continuous culture in media containing glucose as the limiting carbon source and various amines as the sole nitrogen source. Enzyme activities were measured when the cultures had reached a steady state. The results, summarized in Table 1 $(a, b)$, show an increase in the activities of amine oxidase and catalase in both organisms when alkylated amines instead of ammonium sulphate were used as the sole nitrogen source. Because these two enzymes have been shown to play a key role in methylamine metabolism (Zwart et al., 1980), it is very likely that they are also involved in the metabolism of the other alkylated amines studied. During studies with cell-free extracts, evidence was obtained that amine oxidase can only oxidize primary alkylated amines (data not shown). A similar behaviour has been reported for the amine oxidase purified from $C$. boidinii (Haywood \& Large, 1981). This means that secondary and tertiary alkylated amines must be de-alkylated to methylamine or ethylamine, before a further oxidation mediated by amine oxidase is possible. The exact nature of the enzymes performing these initial de-alkylation reactions is unknown. Probably NADHdependent tertiary and secondary amine mono-oxygenases play a role in these reactions (Green \& Large, 1983).

When methylated amines were used as the sole nitrogen source, a distinct increase was observed in the specific activities of formaldehyde and formate dehydrogenases, indicating that formaldehyde was completely oxidized to $\mathrm{CO}_{2}$ (Table $1 a, b$ ). This view was further strengthened 
Table 1. Specific enzyme activities in cell-free extracts of $C$. utilis and $H$. polymorpha grown in continuous cultures $\left(D=0.13 h^{-1}\right)$ in media containing glucose $(0.25 \% \mathrm{w} / \mathrm{v})$ as the limiting carbon source and ammonium sulphate or an amine (approx. $40 \mathrm{mM}$ ) as the sole nitrogen source

In C. utilis alcohol oxidase was not detectable and isocitrate lyase and triokinase were not measured. See Methods for specific activity units.

$\begin{array}{cccccc}\text { Amine } & \text { Formaldehyde } & \text { Formate } \\ \text { dehydro- } & \text { dehydro- } \\ \text { Nitrogen source } & \text { genase } & \text { Alcohol } & \text { Trio- } & \begin{array}{c}\text { Iso- } \\ \text { citrate } \\ \text { oxidase }\end{array}\end{array}$

Ammonium sulphate

Methylamine

Dimethylamine

Trimethylamine

Ethylamine

Diethylamine

Ammonium sulphate

Methylamine

Dimethylamine

Trimethylamine

Ethylamine

Diethylamine (a) C. utilis

$\begin{array}{rr}150 & 5 \\ 1750 & 220 \\ 2500 & 250 \\ 1460 & 97 \\ 370 & 5 \\ 530 & 5\end{array}$

(b) H. polymorpha

$\begin{array}{rrr}9 & 11 & 177 \\ 1765 & 60 & 1542 \\ 1260 & 112 & 1633 \\ 950 & 103 & 1891 \\ 10 & 18 & 27 \\ 100 & 15 & 15\end{array}$

$\begin{array}{rr}51 & 30 \\ 30 & 9 \\ 33 & 5 \\ 42 & 1 \\ 0 & 19 \\ 2 & 46\end{array}$

by the observation that during growth on methylated amines excretion of formaldehyde or formate in the culture supernatant generally did not occur; only very low concentrations of formate (approx. $1 \mathrm{~mm}$ ) were measured in supernatants of $C$. utilis cultures grown on dimethylamine or trimethylamine. In the case of growth at the expense of ethylated amines the specific activities of formaldehyde and formate dehydrogenases were relatively low, reflecting the fact that these compounds were not metabolized via formaldehyde but via acetaldehyde. No accumulation of acetaldehyde or acetate was detectable in the culture supernatant. The results obtained with $H$. polymorpha were comparable to those obtained with $C$. utilis (Table $1 a, b$ ). However, in this methylotrophic yeast, the enzyme alcohol oxidase, which plays a key role in the metabolism of methanol, underwent drastic variations in specific activity in response to the different growth conditions (Table $1 b$ ). This enzyme was not detected in the non-methylotrophic yeast $C$. utilis. The presence of this enzyme during growth of $H$. polymorpha in continuous cultures in media without methanol has been observed before and is thought to be due to derepression of its synthesis under conditions of carbon limitation (Eggeling \& Sahm, 1978; Egli et al., 1980). During growth in the presence of methylated amines, the specific activity of alcohol oxidase in glucose-limited $H$. polymorpha cells had markedly increased, whereas with ethylated amines its activity was even lower than in cells grown in the presence of ammonium sulphate (Table $1 b$ ). One of the key enzymes of formaldehyde assimilation via the xylulose monophosphate pathway in $H$. polymorpha, namely triokinase (van Dijken et al., 1978), was present during growth in the presence of ammonium sulphate or methylated amines, but its activity was very low in media containing ethylated amines (Table $1 b$ ). The activity of isocitrate lyase, an enzyme involved in the metabolism of ethanol and acetate (Kornberg, 1966), did not differ greatly between cultures grown with ammonium sulphate and those grown with ethylated amines. This indicated that conversion of acetaldehyde obtained from the latter group of amines via the glyoxylate cycle is probably insignificant. From the observed enzyme patterns it can be concluded that amine oxidase plays a role in the metabolism of all the alkylated amines studied. The liberated alkyl groups were subsequently further metabolized and oxidized by way of their respective dehydrogenases or used in biosynthetic processes since they did not accumulate in the culture supernatants. 
Table 2. Specific enzyme activities in cell-free extracts of $C$. utilis grown in continuous culture $\left(D=0 \cdot 10 h^{-1}\right)$ in media containing glycerol as the carbon source and ammonium sulphate or methylamine as the nitrogen source

Carbon limitation was established in media containing $0.1 \%(\mathrm{w} / \mathrm{v})$ glycerol and $40 \mathrm{~mm}$-ammonium sulphate or methylamine. Under nitrogen limitation the medium contained $0.3 \%$ glycerol and 5 mM-ammonium sulphate or methylamine. See Methods for specific activity units. GDH, glutamate dehydrogenase; GS, glutamine synthetase; GOGAT, glutamate synthase.

\begin{tabular}{|c|c|c|c|c|c|c|c|}
\hline \multirow[b]{2}{*}{ Nitrogen source } & \multirow[b]{2}{*}{$\begin{array}{l}\text { Limiting } \\
\text { substrate }\end{array}$} & \multicolumn{6}{|c|}{ Specific activity } \\
\hline & & $\begin{array}{l}\text { Amine } \\
\text { oxidase }\end{array}$ & Catalase & $\begin{array}{c}\text { GDH- } \\
\text { NADH }\end{array}$ & $\begin{array}{c}\text { GDH- } \\
\text { NADPH }\end{array}$ & GS & GOGAT \\
\hline Ammonium sulphate & $\mathrm{C}$ & 0 & $1 \cdot 7$ & 60 & 63 & $7 \cdot 5$ & $11 \cdot 5$ \\
\hline Ammonium sulphate & $\mathbf{N}$ & 18 & $3 \cdot 5$ & 12 & 618 & 11 & 34 \\
\hline Methylamine & $\mathrm{C}$ & 42 & 20 & 30 & 915 & 16 & 45 \\
\hline Methylamine & $\mathbf{N}$ & 18 & $3 \cdot 5$ & 9 & 643 & 14 & 49 \\
\hline
\end{tabular}

\section{Effect of alkylated amine utilization on the activity of enzymes involved in ammonia assimilation}

The assimilation of ammonium ions in yeasts proceeds via pathways in which glutamate plays a central role. In most species glutamate is formed via incorporation of ammonia into 2-oxoglutarate by a reaction catalysed by NADPH-dependent glutamate dehydrogenase (GDHNADPH; Brown, 1976). A condition of ammonium limitation in the medium is generally reflected in a sharp increase in the activity of this enzyme (Marzluf, 1981). In some species, however, low extracellular ammonium concentrations resulted in an increase in the specific activity of the enzymes of the GS-GOGAT system, glutamine synthetase and glutamate synthase, while the activity of GDH-NADPH remained low (Brown, 1976). In order to investigate which of these ammonium-assimilating enzymes were involved in $C$. utilis, the cells were grown in continuous culture in media containing glycerol as the carbon source and ammonium sulphate or methylamine as the nitrogen source, under either carbon or nitrogen limitation. The results, summarized in Table 2, show that in C. utilis the activity of assimilatory GDH-NADPH had markedly increased under ammonium-limiting conditions. Similar results were obtained during growth in the presence of methylamine as the sole nitrogen source, while the activity of the enzymes of the GS-GOGAT system increased comparatively little under these conditions. Thus, the major pathway of ammonia assimilation $C$. utilis involves incorporation of ammonium ions into 2-oxoglutarate mediated by GDH-NADPH. Similar observations were made in $H$. polymorpha (results not shown).

In order to investigate whether the increase in GDH-NADPH activity in $C$. utilis and $H$. polymorpha observed during methylamine utilization was a general phenomenon associated with amine utilization, the organisms were grown in continuous culture under glucose limitation in the presence of alkylated amines. Utilization of the different amines by $C$. utilis (Table $3 a$ ) and $H$. polymorpha (Table $3 b$ ) was invariably associated with a significant increase in specific activity of GDH-NADPH, while the activity of GDH-NADH was not affected. The same response was observed after growth of $C$. utilis (Table 2) and $H$. polymorpha (data not shown) under ammonium limitation. In the experiments summarized in Table 3 , however, the organisms were grown under carbon limitation, since, at steady state, no residual glucose was detected in the culture supernatant and only a small amount of the amines initially present in the media had been used (Table 3). In fact, a calculation of the amount of nitrogen required for the synthesis of cell material (Table 3) showed that just sufficient amine was oxidized to meet this requirement. Free ammonia was never detected in the culture supernatants. Apparently, in these organisms control mechanisms exist which allow an accurate adjustment of the rate of amine oxidation to the requirement of the cells for nitrogen. Physiologically, this could result in a condition of ammonia limitation inside the cell during growth at the expense of amines. This may also explain the observed high activities of GDH-NADPH under these conditions. 
Table 3. Specific activity of enzymes, amount of amine consumed and yield during growth of $C$. utilis and $H$. polymorpha in a glucose-limited continuous culture

See Table 1 for details of the culture conditions.

\begin{tabular}{|c|c|c|c|c|c|}
\hline \multirow{3}{*}{ Nitrogen source } & \multicolumn{2}{|c|}{$\begin{array}{l}\text { Specific activity } \\
{\left[\mathrm{nmol} \mathrm{min}^{-1}\right.} \\
\left.(\mathrm{mg} \text { protein })^{-1}\right]\end{array}$} & \multicolumn{2}{|c|}{$\begin{array}{l}\text { Amount of } \\
\text { amine consumed } \\
(\mathrm{mM})\end{array}$} & \multirow{3}{*}{$\begin{array}{l}\text { Yield [g cells } \\
\text { (g glucose } \\
\text { consumed })^{-1} \text { ] }\end{array}$} \\
\hline & GDH-NADPH & GDH-NADH & Observed & Calculated* & \\
\hline & \multicolumn{4}{|c|}{ (a) C. utilis } & \\
\hline Ammonium sulphate & 137 & 20 & - & - & 0.616 \\
\hline Methylamine & 2780 & ND & $6 \cdot 5$ & $6 \cdot 0$ & 0.606 \\
\hline Dimethylamine & 2716 & ND & $7 \cdot 1$ & $6 \cdot 0$ & 0.602 \\
\hline Trimethylamine & 1557 & 12 & 5.9 & $5 \cdot 8$ & 0.602 \\
\hline Ethylamine & 1005 & 28 & $6 \cdot 8$ & $6 \cdot 8$ & 0.694 \\
\hline Diethylamine & 1150 & 13 & ND & ND & 0.898 \\
\hline \multicolumn{6}{|c|}{ (b) H. polymorpha } \\
\hline Ammonium sulphate & 155 & $97 \cdot 8$ & - & - & 0.563 \\
\hline Methylamine & 2823 & $25 \cdot 2$ & $6 \cdot 5$ & $6 \cdot 2$ & $0 \cdot 563$ \\
\hline Dimethylamine & 1624 & $51 \cdot 0$ & ND & ND & ND \\
\hline Trimethylamine & 1848 & $36 \cdot 0$ & $5 \cdot 3$ & $6 \cdot 7$ & 0.608 \\
\hline Ethylamine & 2043 & $51 \cdot 0$ & $6 \cdot 6$ & $7 \cdot 6$ & 0.700 \\
\hline Diethylamine & 1799 & $25 \cdot 2$ & ND & ND & 0.839 \\
\hline
\end{tabular}

Effect of utilization of alkylated amines on the cell yield of C. utilis and H. polymorpha

Utilization of alkylated amines as a nitrogen source in yeasts invariably results in the production of their respective aldehydes (see above and Fig. 1). Since accumulation of these aldehydes in the culture supernatants was not observed, their further utilization, i.e. their complete oxidation to $\mathrm{CO}_{2}$ and water resulting in the production of reduced nicotinamide nucleotides, or their conversion to cell material, should, in a carbon- and/or energy-limited continuous culture, be reflected in an increase in cell yield compared to that obtained with growth in the presence of ammonium sulphate. The results of a study of the effect of the utilization of amines on the cell yields of $C$. utilis and $H$. polymorpha, grown in a glucose-limited continuous culture containing ammonium sulphate or various alkylated amines as the nitrogen source in the feed, are shown in Table $3(a, b)$. The $C$. utilis cultures showed very little variation in the amount of cell material synthesized during growth in the presence of ammonium sulphate or methylated amines as the nitrogen source. Only ethylamine and diethylamine utilization resulted in an increase in cell yield of about 13 and $46 \%$, respectively. In the case of $H$. polymorpha, the cell yield increased by $8 \%$ during growth in the presence of trimethylamine and by 24 and $49 \%$ with ethylamine and diethylamine, respectively. A theoretical calculation was made of the expected increase in cell yield when the aldehydes produced from the amines were used as an energy source only; this revealed that in both strains the observed yield was lower for every amine tested (6-24\% for $C$. utilis and 6-7\% for $H$. polymorpha). A similar calculation for a situation in which acetaldehyde (C. utilis) or formaldehyde and acetaldehyde ( $H$. polymorpha) was used as a carbon and energy source (assumed yield on acetaldehyde $=0.55 \mathrm{~g}$ cell material per $\mathrm{g}$ acetaldehyde consumed; yield on formaldehyde $=0.39 \mathrm{~g}$ cell material per $\mathrm{g}$ formaldehyde consumed) revealed that in this case also for every amine tested the observed yield was lower $(6 \%$ for $C$. utilis and $4.5 \%$ for $H$. polymorpha) except in the case of $H$. polymorpha growing on ethylamine where the observed yield was $14 \%$ higher than the calculated value. A reasonable explanation for these observations is that growth of these yeasts under glucose limitation in the presence of amines as a nitrogen source is associated not only with that of carbon and/or energy limitation (see above) but also with a physiological condition of nitrogen limitation. 


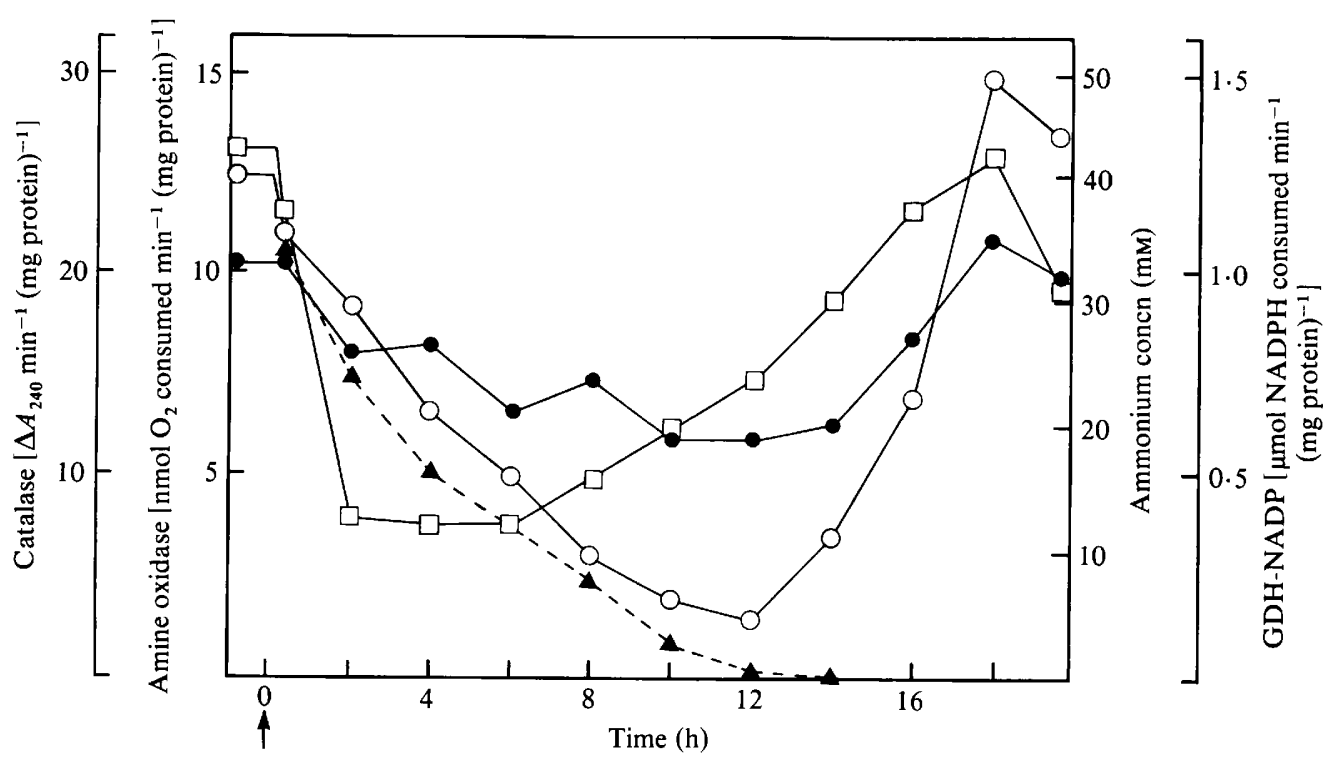

Fig. 2. Effect of addition of ammonium sulphate on the activities of enzymes involved in nitrogen metabolism in $C$. utilis. Cells were grown in a continuous culture $\left(D=0 \cdot 12 \mathrm{~h}^{-1}\right)$ containing ethanol $(0.25 \%, \mathrm{v} / \mathrm{v})$ as the limiting carbon source and methylamine $(40 \mathrm{mM})$ as the nitrogen source. At $t=0$ (arrow) $35 \mathrm{~mm}$-ammonium sulphate was added to the culture. $O$, Amine oxidase; $\odot$, catalase; $\square$, GDH-NADP; $\boldsymbol{\Delta}$, ammonium concentration.

\section{Regulation of amine oxidase synthesis in Candida utilis}

As shown above, the rate of amine utilization in $C$. utilis and $H$. polymorpha is strictly regulated. When compared to cell material, methylamine and ethylamine possess a rather high nitrogen to carbon ratio, and utilization of such compounds as carbon sources would necessarily bring about excretion of excess ammonium ions. The absence of free ammonium ions in culture supernatants (see above) after growth in the presence of alkylated amines therefore indicated a careful adjustment of the amount of ammonia produced to the requirement of the cells. Since ammonium itself could be involved as a controlling factor, for instance through effects on amine oxidase activity and/or synthesis or amine uptake, we decided to study the regulation of these processes in more detail.

In cell-free extracts of $C$. utilis or H. polymorpha, ammonium ions used in concentrations up to $100 \mathrm{~mm}$ had no direct inhibitory effect on the amine oxidase activity. The regulation of amine oxidase synthesis in C.utilis was studied in more detail in chemostat cultures containing glycerol as the carbon source and ammonium sulphate or methylamine as the nitrogen source. The results summarized in Table 2 show that the enzyme, which is absent in glycerol-limited cultures in the presence of ammonium sulphate, is synthesized when such cultures are grown under conditions of ammonia limitation. Therefore its synthesis is not dependent upon the presence of methylamine in the medium. However, during growth in the presence of excess methylamine as the nitrogen source, the enzyme displayed its highest activity under glycerol limitation. A significant increase in the activity of catalase was only observed under the latter conditions (Table 2).

We also studied the effect of excess ammonium on amine oxidase synthesis by adding ammonium sulphate ( $35 \mathrm{mM}$ ) to an ethanol-limited culture of $C$. utilis containing methylamine as the nitrogen source. The results obtained indicated that the synthesis of amine oxidase was blocked completely upon addition of ammonium sulphate to the culture. Inactivation of existing enzyme probably did not occur since the decrease of activity observed could be accounted for by dilution as a result of growth and washout (Fig. 2). Since ammonium was used by the cells, its rate of disappearance was slightly faster than the wash-out rate. Catalase decreased slowly in 


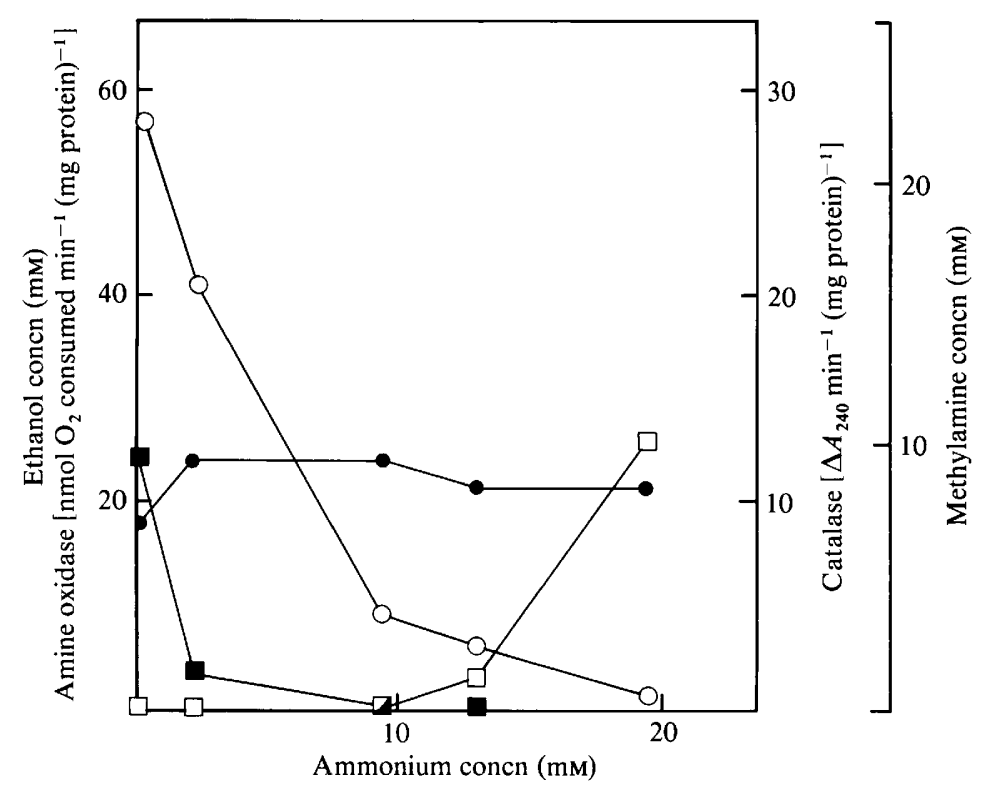

Fig. 3. Effect of a stepwise addition of ammonium sulphate $(0-25 \mathrm{~mm})$ to the medium reservoir of a $C$. utilis culture $\left(D=0.12 \mathrm{~h}^{-1}\right)$ growing initially under nitrogen limitation in a medium with ethanol $(110 \mathrm{mM})$ as the carbon source and methylamine $(5 \mathrm{mM})$ as the nitrogen source, on the specific activities of amine oxidase $(O)$ and catalase $(O)$ and the concentrations of methylamine $(\square)$ and ethanol $(\square)$ in the culture supernatants.

activity whereas a significant part of the GDH-NADP was rapidly inactivated in the first $2 \mathrm{~h}$ following the addition. The activity of this latter enzyme gradually increased again after the ammonium concentration in the culture had decreased below $10 \mathrm{mM}$. Twelve hours after ammonium sulphate addition, when the ammonium concentration in the culture had dropped to a low level, amine oxidase was resynthesized quite rapidly.

The stepwise addition of ammonium sulphate (0-20 mM) to the medium reservoir of a C. utilis culture growing under methylamine limitation on ethanol as the carbon source also resulted in a gradual decrease in amine oxidase activity at steady state (Fig. 3). At ammonium concentrations in the medium above $10 \mathrm{mM}$, sufficient to supply the cells with all the nitrogen necessary for growth, amine oxidase activity had decreased to $5 \%$ of its initial value. When $20 \mathrm{~mm}$ of ammonium sulphate was present in the feed, amine oxidase activity had nearly dropped to zero level and methylamine remained completely unused in the culture supernatant. In this experiment the ethanol concentration in the culture decreased upon addition of ammonia. At ammonia concentrations of $10 \mathrm{~mm}$ and higher in the feed, the concentration of this carbon source was undetectably low, indicating a change-over from nitrogen to carbon limitation.

From these results it can be concluded that synthesis of amine oxidase in $C$. utilis is regulated by a repression/derepression mechanism in which ammonia plays an essential role. Apart from the influence on amine oxidase synthesis, ammonium also strongly inhibited the uptake of methylamine in cells of $C$. utilis. This aspect will be described in detail elsewhere.

\section{Electron microscopy}

The effects of amine utilization, under carbon or nitrogen limitation, on cell ultrastructure were studied in chemostat-grown cells, fixed with $\mathrm{KMnO}_{4}$. Cells of $C$. utilis grown under glycerol limitation in the presence of excess ammonium sulphate (Fig. $4 a$ ) showed an ultrastructure largely comparable to that described for glucose-grown cells (Zwart et al., 1980). These cells contained, besides the usual cell organelles such as nuclei, vacuoles and mitochondria, a number of small peroxisomes and little or no storage material. However, when such cultures were grown in the presence of excess methylamine they contained several large peroxisomes (Fig. $4 b$ ) and, in this respect, resembled cells grown in batch culture on glucose and methylamine 

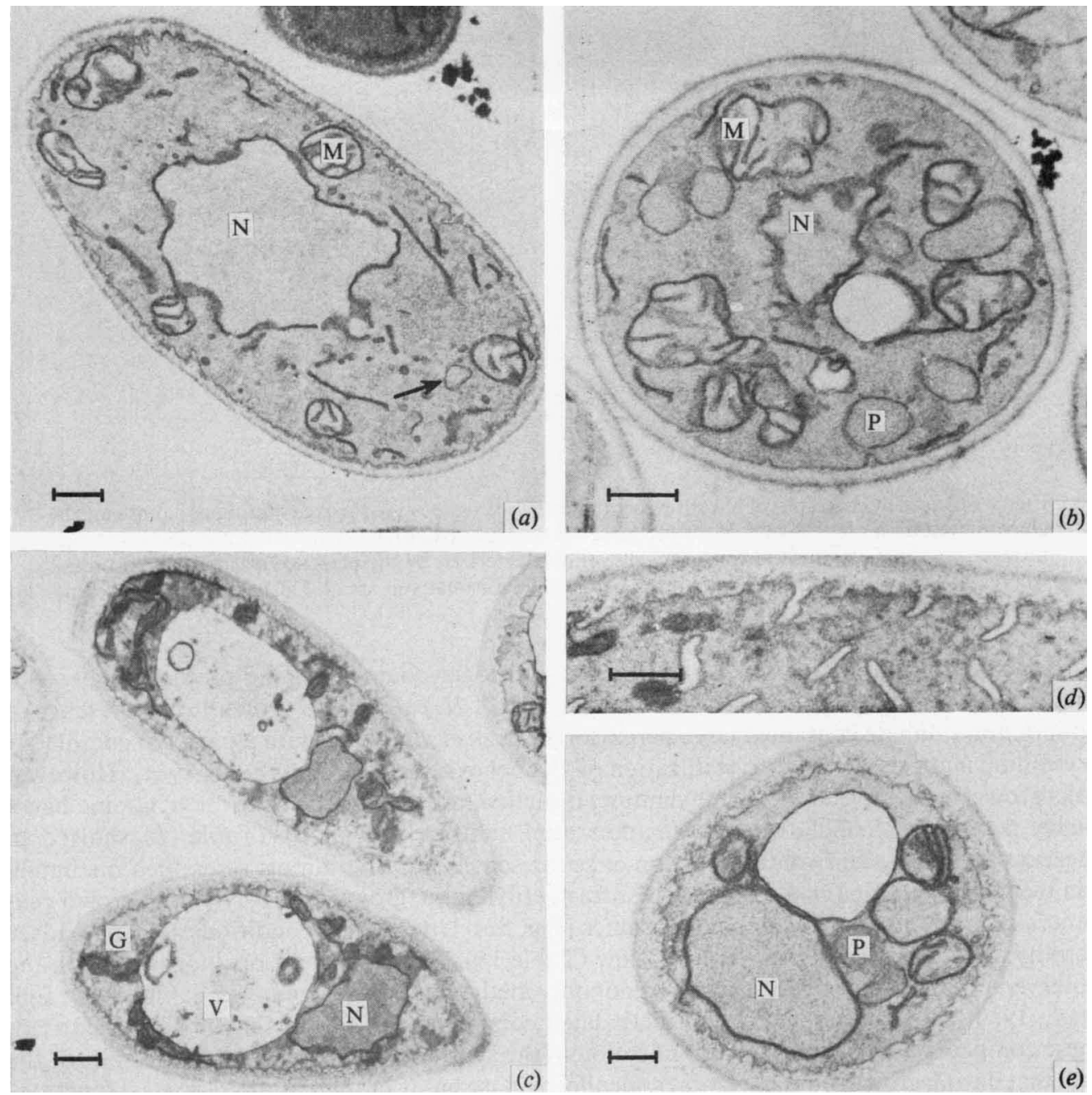

(c)

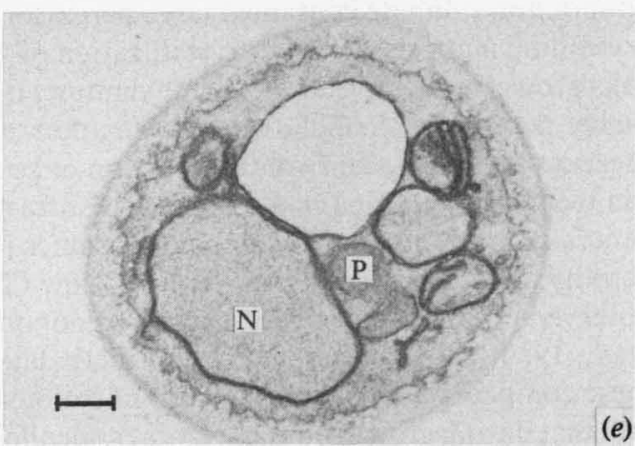

Fig. 4. Electron micrographs of ultra-thin sections of $\mathrm{KMnO}_{4}$-fixed Candida utilis cells grown in continuous culture $\left(D=0 \cdot 13 \mathrm{~h}^{-1}\right)$. Abbreviations: $\mathrm{G}$, glycogen; $\mathrm{M}$, mitochondrion; $\mathrm{N}$, nucleus; $\mathrm{P}$, peroxisome; V, vacuole. The bar markers represent $0.5 \mu \mathrm{m}$. (a) A cell grown under glycerol limitation and excess ammonium sulphate, containing small peroxisomes (arrow). (b) A cell grown under glycerol limitation and excess methylamine, containing several large peroxisomes. (c) Elongated cells grown on glycerol and limiting amounts of ammonium sulphate, with a high glycogen content and thick cell walls. $(d)$ Detail of a cell grown as for $(c)$, showing strongly invaginated cell membrane. (e) Section of a cell grown on glycerol in the presence of limiting amounts of methylamine. Note the resemblance to the cells in $(c)$.

(Zwart et al., 1980). Also in these cells generally little or no storage material was observed. During growth of the cultures under ammonium sulphate limitation, the cells were more elongated, had a relatively thick cell wall with large protrusions and contained large amounts of glycogen (Figs $4 c, d$ ). Cells grown under methylamine limitation showed very similar features (Fig. $4 e$ ). During growth in the presence of dimethylamine or trimethylamine, and especially in the presence of ethylamine or diethylamine, however, $C$. utilis cells often contained several lipid droplets as was also evident in freshly prepared cell-free extracts. Thus, with respect to the accumulation of storage material, cells grown in the presence of excess of an alkylated amine are intermediate between those grown under carbon limitation in the presence of ammonium sulphate and those grown under nitrogen limitation. These observations are in agreement with the conclusion based on enzymic evidence that cells, even when grown under conditions of 

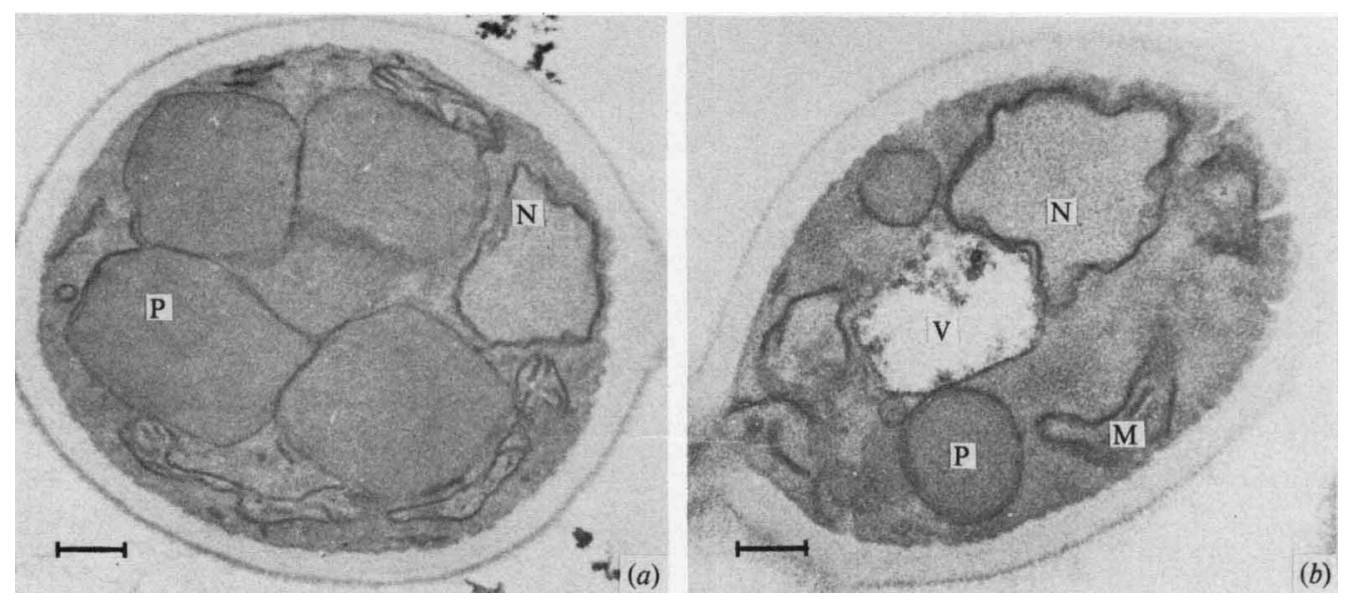

Fig. 5. Electron micrographs of ultrathin sections of $H$. polymorpha grown in a continuous culture under glucose limitation $\left(D=0.13 \mathrm{~h}^{-1}\right)$, in the presence of dimethylamine $(a)$ and diethylamine $(b)$ as the nitrogen source. Dimethylamine-grown cells are characterized by the presence of large peroxisomes, whereas during growth on diethylamine these organelles are relatively small. The bar markers represent $0.5 \mu \mathrm{m}$; abbreviations as for Fig. 4 .

carbon limitation in the presence of amines as a nitrogen source, respond physiologically as if they are also nitrogen limited. Glucose-limited cells of $\boldsymbol{H}$. polymorpha grown in the presence of ammonium sulphate contained large peroxisomes (Egli et al., 1980), with a partly or completely crystalline matrix due to the crystallization of alcohol oxidase (Veenhuis et al., 1981). However, cells grown in the presence of methylamine, dimethylamine (Fig. 5a) or trimethylamine had a higher activity of alcohol oxidase than ammonium sulphate-grown cells (Table $1 b$ ), showed an increase in number and volume fraction of peroxisomes and thus almost resembled methanollimited cells (Veenhuis et al., 1976). In contrast, ethylamine-grown or diethylamine-grown cells generally contained rather small peroxisomes (Fig. $5 b$ ). Under these conditions alcohol oxidase activity and catalase activity were very low (Table $1 b$ ). These observations, together with the observed enzyme activities, suggest that not only methanol itself (Eggeling \& Sahm, 1980; Egli et al., 1980) but also the presence of methylated compounds, or formaldehyde generated from these compounds, may cause an amplification of the synthesis of alcohol oxidase, in spite of the fact that during growth on these amines, alcohol oxidase has no apparent physiological function.

\section{DISCUSSION}

The yeasts Candida utilis and Hansenula polymorpha are both able to grow in media containing glucose as the carbon source and various alkylated amines as the sole source of nitrogen. Compared to ammonium sulphate-grown cells, cells of $C$. utilis grown in the presence of methylated amines had high activities of amine oxidase and catalase, and contained several large peroxisomes. In a previous paper (Zwart et al., 1980), the localization of amine oxidase and catalase in these organelles has been demonstrated. Recently Green \& Large (1983) showed that NADH-dependent mono-oxygenases are involved in the demethylation of trimethylamine and dimethylamine in C. utilis. Amine oxidase is also an important enzyme in the metabolism of trimethylamine and dimethylamine (see Table $1 a$ ), and oxidation of trimethylamine and dimethylamine in this organism probably proceeds as follows:

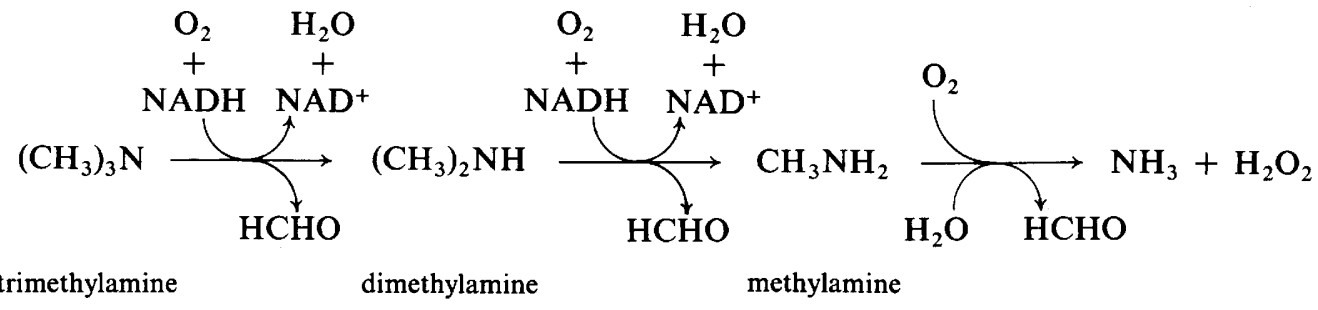


Growth in the presence of trimethylamine, dimethylamine and methylamine was also associated with high activities of formaldehyde and formate dehydrogenases. The presence of these enzymes ensures the further metabolism of formaldehyde that is generated in the demethylation reactions. In the case of growth with ethylated amines, the further oxidation of acetaldehyde, liberated from ethylamine and diethylamine, was not established enzymically in the present work. However, the absence of acetaldehyde and acetate in culture supernatants indicated that this compound is metabolized by the cells. These results show that amine oxidase is involved in the oxidation of all the amines mentioned above, and since this enzyme is located in peroxisomes it must be concluded that these organelles play an essential role in the metabolism of the nitrogen source during growth of $C$. utilis in media containing an alkylated amine as the sole source of nitrogen.

Observations similar to those reported for $C$. utilis were made in $H$.polymorpha, although in this organism the situation was more complex because of the presence of high activities of peroxisomal alcohol oxidase in cells grown in a glucose-limited continuous culture with ammonium sulphate, methylamine, dimethylamine or trimethylamine as the sole nitrogen source. Derepression of the synthesis of this enzyme under various conditions is well known (Eggeling \& Sahm, 1978, 1980; Egli et al., 1980). Our results obtained with cells grown under glucose limitation in the presence of ammonium sulphate as the nitrogen source are in complete agreement with those reported by Egli et al. (1980). Eggeling \& Sahm (1980) reported an increased level of alcohol oxidase activity in $H$. polymorpha when the organism was grown in a carbon-limited continuous culture on a mixture of, for instance, glucose and methanol. According to these authors the increase in activity was, at least partly, due to the presence of methanol itself. From our experiments with cells of $H$. polymorpha in which methylamine, dimethylamine or trimethylamine were used as the sole source of nitrogen, it must be concluded that also in the absence of methanol, but in the presence of a methylated amine, alcohol oxidase synthesis becomes strongly derepressed. This results in levels of this enzyme as high as those observed in methanol-limited cells (van Dijken et al., 1976; Egli et al., 1980). In contrast, alcohol oxidase activity was very low in cultures using ethylamine or diethylamine as a nitrogen source. This is probably caused by the repressive effect of the $\mathrm{C}_{2}$-containing carbon moiety of these organic nitrogen compounds. Compared to growth in the presence of ammonium sulphate, utilization of an amine by cells of $H$. polymorpha was always associated with an increase in amine oxidase activity. In this organism, alcohol oxidase and amine oxidase were localized in the same peroxisomes during growth on methanol and methylamine (Veenhuis et al., 1981). Therefore it can be concluded that in $H$. polymorpha, as in $C$. utilis, peroxisomes play an essential role in nitrogen metabolism during growth in the presence of an alkylated amine as the sole nitrogen source.

Several lines of evidence indicate that growth of the two yeasts under glucose limitation with an amine present as the sole nitrogen source in a high concentration not only resulted in apparent carbon and energy limitation but also in a physiological condition of nitrogen limitation (Table 3). Under these conditions accumulation of ammonia in the culture vessel was never observed and only minimal amounts of the amines were used; in fact, as could be calculated, just sufficient to account for the nitrogen required for the synthesis of the observed amount of cell material produced. Growth with amines as the sole nitrogen source also resulted in a drastic increase in the activity of NADP-dependent glutamate dehydrogenase. This enzyme plays a major role in ammonia assimilation in a number of yeasts, whereas glutamine synthetase/glutamate synthase are less important (Brown, 1976). An increased activity of GDHNADP was also observed during growth of C. utilis (see Table 2) and Saccharomyces cerevisiae (Brown, 1976) under ammonia limitation. In our experiments (Table 3) residual glucose could not be detected in the culture supernatants of $C$. utilis and $H$. polymorpha when these organisms were grown in the presence of amines as a nitrogen source. Together with the ultrastructural observations (Fig. $4 b-e$ ) this evidence indicates that the organisms are actually growing under both carbon and nitrogen limitation.

Utilization of an alkylated amine via an amine oxidase is always accompanied by the production of an aldehyde, formaldehyde in the case of methylated amines and acetaldehyde in the case of ethylated amines. Complete oxidation of these aldehydes to carbon dioxide and water 
will probably result in the production of ATP. In an energy-limited continuous culture, such an extra ATP production is expected to result in an increase in cell yield. On the other hand, in yeasts with the capacity for aldehyde assimilation, production of an aldehyde may also lead to increased cell mass production, provided that the cells are growing under carbon limitation. Cells of $C$. utilis can assimilate acetaldehyde, while cells of $H$. polymorpha can synthesize cell material from formaldehyde also. In our experiments with $C$. utilis only growth in media containing ethylated amines as a nitrogen source resulted in an increase in cell yield when compared to growth in the presence of ammonium sulphate. This extra production of cell material, however, was somewhat smaller than expected on the basis of theoretical calculations. In the experiments with $H$. polymorpha not only growth in the presence of ethylated amines resulted in an increase in cell yield, but also growth on trimethylamine. In this organism too, the increase was somewhat lower than expected on the basis of theoretical considerations, except for growth with ethylamine. This could be due to conversion of part of the amine-carbon into reserve material such as lipids, a phenomenon which was in fact frequently observed in cells grown with ethylated amines (Fig. $5 b$ ).

The physiological condition of nitrogen limitation during growth at the expense of amines as a nitrogen source is probably caused by feedback repression of the synthesis of amine oxidase mediated by ammonium ions. In the presence of these ions the synthesis of this enzyme in $C$. utilis is repressed, whereas under ammonia limitation, even in the absence of an amine, the repression was released. Amine oxidase was the only peroxisomal enzyme involved in nitrogen metabolism that was detected during growth of this yeast under ammonia limitation. Activities of D-amino acid oxidase or uric acid oxidase, which may also play a role in the cell's nitrogen metabolism under certain growth conditions (K. B. Zwart, unpublished), were not found. A repression/derepression mechanism controlling the synthesis of an enzyme involved in nitrogen catabolism in microbial cells is not very common although some examples have been reported. For instance, synthesis of arginase in several micro-organisms (Abdelal, 1979) and of xanthine dehydrogenase and urate oxidase in Streptomyces cyanogenus (Ohe \& Watanabe, 1978) is regulated by nitrogen catabolite repression in which ammonia, or a metabolite of ammonia, acts as repressor molecule. A repression/derepression mechanism that controls the synthesis of enzymes involved in carbon metabolism is more common and has for instance been described for the enzymes involved in the metabolism of methanol in $H$. polymorpha (Eggeling \& Sahm, 1980; Egli et al., 1980) and for the Calvin cycle enzymes in Pseudomonas oxalaticus (Dijkhuizen \& Harder, 1979). Repression of amine oxidase synthesis was also observed in $H$. polymorpha after transfer of methanol/methylamine-grown cells into methanol/ammonium sulphatecontaining media (Veenhuis et al., 1981). This regulatory effect of ammonium on the metabolism of amines may also explain the inability of yeasts to grow on these compounds as the sole carbon source (van Dijken \& Bos, 1981). Utilization of amines as a carbon source is necessarily accompanied by excretion or accumulation of excess ammonium, because of the high nitrogen to carbon ratio in these compounds. This will lead to a repression of amine oxidase synthesis and ultimately to cessation of growth.

The investigations were supported (in part) by the Foundation for Fundamental Biological Research (BION) which is subsidized by the Netherlands Organization for the Advancement of Pure Research (ZWO). We are indebted to Wim de Koning for his part in experiments on the regulation of amine oxidase synthesis and to Dr L. Dijkhuizen and M. Veenhuis for valuable discussions.

\section{REFERENCES}

Abdelal, A. (1979). Arginine catabolism by microorganisms. Annual Review of Microbiology 33, 139168.

BROWN, C. M. (1976). Nitrogen metabolism in bacteria and fungi. In Continuous Cultures, Applications and New Fields, vol. 6, pp. 170 183. Edited by A. C. R. Dean, D. C. Ellwood, C. G. T. Evans \& J. Melling. Chichester: Ellis Horwood.
VAN DiJken, J. P. \& Bos, P. (1981). Utilization of amines by yeasts. Archives of Microbiology 128, 302324.

van Dijken, J. P. \& Veenhuis, M. (1980). Cytochemical localization of glucose oxidase in peroxisomes of Aspergillus niger. European Journal of Applied Microhiology and Biotechnology 9, 275-283.

van Dijken, J. P., Otto, R. \& Harder, W. (1976). 
Growth of Hansenula polymorpha in a methanollimited chemostat. Physiological responses due to the involvement of methanol oxidase as a key enzyme in methanol metabolism. Archives of Microbiology 111, 137-144.

van DiJken, J. P., Harder, W., Beardsmore, A. J. \& QUAYLE, J. R. (1978). Dihydroxyacetone: an intermediate in the assimilation of methanol by yeasts? FEMS Microbiology Letters 4, 97-102.

Dijkhuizen, L. \& HaRder, W. (1979). Regulation of autotrophic and heterotrophic metabolism in Pseudomonas oxalaticus OX1. Growth on mixtures of acetate and formate in continuous culture. Archives of Microbiology 123, 47-53.

Dixon, G. H. \& Kornberg, H. L. (1959). Assay methods for key enzymes of the glyoxylate cycle. Biochemical Journal 72, 3.

EgGeling, L. \& SAHM, H. (1978). Derepression and partial insensitivity to carbon catabolite repression of the methanol dissimilating enzymes in Hansenula polymorpha. European Journal of Applied Microbiology and Biotechnology 5, 197-202.

EGGELING, L. \& SAHM, H. (1980). Regulation of alcohol oxidase synthesis in Hansenula polymorpha: oversynthesis during growth on mixed substrates and induction by methanol. Archives of Microbiology 127, 119-124.

Egli, T., van Dijken, J. P., Veenhuis, M., Harder, W. \& FIECHTER, A. (1980). Methanol metabolism in yeasts. Regulation of the synthesis of catabolic enzymes. Archives of Microbiology 124, 115-123.

Green, J. \& LARGE, P. J. (1983). Oxidation of dimethylamine and trimethylamine in methazotrophic yeasts by microsomal mono-oxygenases sensitive to carbon monoxide. Biochemical and Biophysical Research Communications 113, 900-907.

Haywood, G. W. \& Large, P. J. (1981). Microbial oxidation of amines. Distribution, purification and properties of two primary amine oxidases from the yeast Candida boidinii grown on amines as sole nitrogen source. Biochemical Journal 199, 187 201.

KORNBERG, H. L. (1966). Anaplerotic sequences and their role in metabolism. In Essays in Biochemistry, vol. 2, pp. 1-32. Edited by P. N. Campbell \& G. D. Greville. London \& New York: Academic Press.

LaAnbroek, H. J., Kingma, W. \& VeldKamp, H. (1977). Isolation of an aspartate-fermenting free- living Campylobacter species. FEMS Microbiology Letters 1, 99-102.

LANG, E. \& LANG, H. (1972). Spezifische Farbreaktion zum direkten Nachweis der Ameisensäure. Fresenius Zeitschrift für analytische Chemie 260, 8-10.

LüCK, H. (1963). Catalase. In Methods of Enzymatic Analysis, pp. 885-894. Edited by H. U. Bergmeyer. New York \& London: Academic Press.

Marzluf, G. A. (1981). Regulation of nitrogen metabolism and gene expression in fungi. Microbiological Reviews 45, 437-461.

MECKE, D. (1974). L-Glutamine, determination with glutamine synthetase. In Methods of Enzymatic Analysis, pp. 1716-1719. Edited by H. U. Bergmeyer. New York \& London: Academic Press.

Meiberg, J. B. M. \& Harder, W. (1979). Dimethylamine dehydrogenase from Hyphomicrobium $X$. Purification and some properties of a new enzyme that oxidizes secondary amines. Journal of General Microbiology 115, 49-58.

$\mathrm{N}_{\text {ASH, }}$ T. (1953). The colorimetric estimation of formaldehyde by means of the Hantsch reaction. Biochemical Journal 55, 416-421.

OHE, T. \& WATANABE, Y. (1978). Effect of glucose and ammonium on the formation of xanthine dehydrogenase and urate oxidase. Journal of Fermentation Technology 56, 477-483.

Roon, R. J., Even, H. L. \& Larimore, F. (1973). Glutamate synthase: properties of the reduced nicotinamide adenine dinucleotide dependent enzyme from Saccharomyces cerevisiae. Journal of Bacteriology 118, 89-95.

Veenhuis, M., van Dijken J. P. \& Harder, W. (1976). Cytochemical staining studies on the localization of methanol oxidase and other oxidases in peroxisomes of methanol-grown Hansenula polymorpha. Archives of Microbiology 111, 123-135.

Veenhuis, M., ZWart, K. B. \& Harder, W. (1981). Biogenesis and turnover of peroxisomes involved in the concurrent oxidation of methanol and methylamine in Hansenula polymorpha. Archives of Microhiology 129, 35-41.

ZWart, K., Veenhuis, M., van Dijken, J. P. \& HARDER, W. (1980). Development of amine oxidase containing peroxisomes in yeasts during growth on glucose in the presence of methylamine as the sole nitrogen source. Archives of Microbiology 126, 117126 . 